\title{
A NOTE ON GENERALIZED OPIAL TYPE INEQUALITIES
}

\author{
B. G. PACHPATTE
}

\begin{abstract}
In the present note we establish some new inequalities involving integrals of functions and their derivatives which in the special cases yield the well known Opial inequality and some of its generalizations.
\end{abstract}

\section{Introduction}

The integral inequality

$$
\int_{a}^{b} F^{\prime}(|u(x)|)\left|u^{\prime}(x)\right| d x \leq F\left(\int_{a}^{b}\left|u^{\prime}(x)\right| d x\right)
$$

valid for absolutely continuous function $u(x)$ defined on $[a, b]$ with $u(a)=0$ and $F(z)$ is a convex increasing function for $z \geq 0$ with $F(0)=0$, is established in 1967 by $\mathbb{E}$. $\mathbb{K}$. Godunova and V. I. Levin [1]. An interesting feature of the integral inequality established in (1) is that in the special case it yields the well known inequality proved earlier by Z. Opial [5] (see, [3, Theorem $2^{\prime}$, p. 154]). In 1972, G. I. Rozanova [7] obtained a further generalization of the inequality (1) in the following form

$$
\int_{a}^{b} F^{\prime}\left(r(x) \phi\left(\frac{|u(x)|}{r(x)}\right)\right) r^{\prime}(x) \phi\left(\frac{\left|u^{\prime}(x)\right|}{r^{\prime}(x)}\right) d x \leq F\left(\int_{a}^{b} r^{\prime}(x) \phi\left(\frac{\left|u^{\prime}(x)\right|}{r^{\prime}(x)}\right) d x\right),
$$

where $u, F$ are the same functions as defined in the inequality (1), $r(x) \geq 0$, $r^{\prime}(x)>0, r(a)=0$ and $\phi(z)$ is a convex increasing function for $z>0$. The main 
object of the present note is to establish some new inequalities of the type (1) and (2) involving integrals of functions and their derivatives which in the special cases yield the well known Opial inequality [3, Theorem $2^{\prime}$, p. 154] and some of its generalizations given by the other investigators.

\section{Statement of Results}

Our main result in this note is established in the following theorem.

Theorem 1. Let $u$ and $v$ be absolutely continuous functions: defined on $[a, b]$ such that $u(a)=v(a)=0$. Let $r(x) \geq 0, r^{\prime}(x)>0, r(a)=0$ and $m(x) \geq 0, m^{\prime}(x)>0, m(a)=0$. Let $F(z)$ and $G(z)$ be nonnegative, continuous, nondecreasing functions for $z \geq 0$ and $F(0)=G(0)=0$ such that $F^{\prime}(z)$ and $G^{\prime}(z)$ exist and are nonnegative, continuous and nondecreasing for $z \geq 0$. If $\phi(z)$ and $\Psi(z)$ are positive, convex and increasing functions for $z>0$, then

$$
\begin{aligned}
& \int_{a}^{b}\left[F\left(r \phi\left(\frac{|u|}{r}\right)\right) G^{\prime}\left(m \Psi\left(\frac{|v|}{m}\right)\right) m^{\prime} \Psi\left(\frac{\left|v^{\prime}\right|}{m^{\prime}}\right)\right. \\
& \left.+G\left(m \Psi\left(\frac{|v|}{m}\right)\right) F^{\prime}\left(r \phi\left(\frac{|u|}{r}\right)\right) r^{\prime} \phi\left(\frac{\left|u^{\prime}\right|}{r^{\prime}}\right)\right] d x \\
\leq & F\left(\int_{a}^{b} r^{\prime} \phi\left(\frac{\left|u^{\prime}\right|}{r^{\prime}}\right) d x\right) G\left(\int_{a}^{b} m^{\prime} \Psi\left(\frac{\left|v^{\prime}\right|}{m^{\prime}}\right) d x\right) .
\end{aligned}
$$

Furthermore, let $p(x)>0$ be defined on $[a, b]$ and $\int_{a}^{b} p(x) d x=1$. If $h(z)$ is a positive, convex and increasing function for $z>0$, then

$$
\begin{aligned}
& \int_{a}^{b}\left[F\left(r \phi\left(\frac{|u|}{r}\right)\right) G^{\prime}\left(m \Psi\left(\frac{|v|}{m}\right)\right) m^{\prime} \Psi\left(\frac{\left|v^{\prime}\right|}{m^{\prime}}\right)\right. \\
& \left.+G\left(m \Psi\left(\frac{|v|}{m}\right)\right) F^{\prime}\left(r \phi\left(\frac{|u|}{r}\right)\right) r^{\prime} \phi\left(\frac{\left|u^{\prime}\right|}{r^{\prime}}\right)\right] d x \\
\leq & F\left(h^{-1}\left(\int_{a}^{b} p h\left(\frac{r^{\prime} \phi\left(\frac{\left|u^{\prime}\right|}{r^{\prime}}\right)}{p}\right) d x\right)\right) \\
& \cdot G\left(h^{-1}\left(\int_{a}^{b} p h\left(\frac{m^{\prime} \Psi\left(\frac{v^{\prime} \mid}{m^{\prime}}\right)}{p}\right) d x\right)\right) .
\end{aligned}
$$


An immediate consequence of Theorem 1 is the following

Corollary 2. Assume that in the hypotheses of Theorem 1 we have $G(z)=$ $z, m=r, v=u, \Psi=\phi$, then

$$
\begin{aligned}
& \int_{a}^{b}\left[F\left(r \phi\left(\frac{|u|}{r}\right)\right)+F^{\prime}\left(r \phi\left(\frac{|u|}{r}\right)\right) r \phi\left(\frac{|u|}{r}\right)\right] r^{\prime} \phi\left(\frac{\left|u^{\prime}\right|}{r^{\prime}}\right) d x \\
\leq & F\left(\int_{a}^{b} r^{\prime} \phi\left(\frac{\left|u^{\prime}\right|}{r^{\prime}}\right) d x\right)\left(\int_{a}^{b} r^{\prime} \phi\left(\frac{\left|u^{\prime}\right|}{r^{\prime}}\right) d x\right),
\end{aligned}
$$

and

$$
\begin{aligned}
& \int_{a}^{b}\left[F\left(r \phi\left(\frac{|u|}{r}\right)\right)+F^{\prime}\left(r \phi\left(\frac{|u|}{r}\right)\right) r \phi\left(\frac{|u|}{r}\right)\right] r^{\prime} \phi\left(\frac{\left|u^{\prime}\right|}{r^{\prime}}\right) d x \\
\leq & F\left(h^{-1}\left(\int_{a}^{b} p h\left(\frac{r^{\prime} \phi\left(\frac{\left|u^{\prime}\right|}{r^{\prime}}\right)}{p}\right) d x\right)\right) \cdot h^{-1}\left(\int_{a}^{b} p h\left(\frac{r^{\prime} \phi\left(\frac{\left|u^{\prime}\right|}{r^{\prime}}\right)}{p}\right) d x\right) .
\end{aligned}
$$

Remark 1 . If we take $F(z)=z^{q}$ where $q \geq 1$ is a constant and hence $F^{\prime}(z)=q z^{q-1}$ in (5), then we get

$$
\int_{a}^{b}\left[r \phi\left(\frac{|u|}{r}\right)\right]^{q} r^{\prime} \phi\left(\frac{\left|u^{\prime}\right|}{r^{\prime}}\right) d x \leq \frac{1}{q+1}\left(\int_{a}^{b} r^{\prime} \phi\left(\frac{\left|u^{\prime}\right|}{r^{\prime}}\right) d x\right)^{q+1} .
$$

Further letting $\phi(z)=z$ in (7) and using the Hölder's inequality with indices $q+1$ and $\frac{q+1}{q}$ on the right side of the resulting inequality, we get

$$
\int_{a}^{b}|u|^{q}\left|u^{\prime}\right| d x \leq \frac{(b-a)^{q}}{q+1} \int_{a}^{b}\left|u^{\prime}\right|^{q+1} d x
$$

which in turn is a slight variant of the inequality established by Yang [8, Theorem 3] and contains as a special case the Opial inequality given in [3, Theorem $2^{\prime}$, p. 154] when $q=1$, see, also [4]. We also note that in the special cases the inequality (6) yields the various inequalities as discussed above. 


\section{Proofs of Theorem 1 and Corollary 2}

From the assumptions of Theorem 1, it is easy to observe that for $x \in[a, b]$,

and

$$
u(x)=\int_{a}^{x} u^{\prime}(t) d t, \quad r(x)=\int_{a}^{x} r^{\prime}(t) d t,
$$

$$
v(x)=\int_{a}^{x} v^{\prime}(t) d t, \quad m(x)=\int_{a}^{x} m^{\prime}(t) d t .
$$

Let $a<x<b$. Then from (9) and (10) we observe that

and

$$
\frac{|u(x)|}{r(x)} \leq \frac{\int_{a}^{x} \frac{r^{\prime}(t)\left|u^{\prime}(t)\right|}{r^{\prime}(t)} d t}{\int_{a}^{x} r^{\prime}(t) d t},
$$

$$
\frac{|v(x)|}{m(x)} \leq \frac{\int_{a}^{x} \frac{m^{\prime}(t)\left|v^{\prime}(t)\right|}{m^{\prime}(t)} d t}{\int_{a}^{x} m^{\prime}(t) d t} .
$$

Since $\phi(z)$ and $\Psi(z)$ are convex and increasing functions for $z>0$, from (11) and (12) and using Jensen's inequality [2, p. 133] we obtain

and

$$
\phi\left(\frac{|u(x)|}{r(x)}\right) \leq \frac{1}{r(x)} \int_{a}^{x} r^{\prime}(t) \phi\left(\frac{\left|u^{\prime}(t)\right|}{r^{\prime}(t)}\right) d t
$$

$$
\Psi\left(\frac{|v(x)|}{m(x)}\right) \leq \frac{1}{m(x)} \int_{a}^{x} m^{\prime}(t) \Psi\left(\frac{\left|v^{\prime}(t)\right|}{m^{\prime}(t)}\right) d t .
$$

Now in view of (13) and (14) we observe that

$$
\begin{aligned}
& \int_{a}^{b}\left[F\left(r \phi\left(\frac{|u|}{r}\right)\right) G^{\prime}\left(m \Psi\left(\frac{|v|}{m}\right)\right) m^{\prime} \Psi\left(\frac{\left|v^{\prime}\right|}{m^{\prime}}\right)\right. \\
& \left.+G\left(m \Psi\left(\frac{|v|}{m}\right)\right) F^{\prime}\left(r \phi\left(\frac{|u|}{r}\right)\right) r^{\prime} \phi\left(\frac{\left|u^{\prime}\right|}{r^{\prime}}\right)\right] d x \\
\leq & \int_{a}^{b}\left[F\left(\int_{a}^{x} r^{\prime} \phi\left(\frac{\left|u^{\prime}\right|}{r^{\prime}}\right) d t\right) G^{\prime}\left(\int_{a}^{x} m^{\prime} \Psi\left(\frac{\left|v^{\prime}\right|}{m^{\prime}}\right) d t\right) m^{\prime} \Psi\left(\frac{\left|v^{\prime}\right|}{m^{\prime}}\right)\right. \\
& \left.+G\left(\int_{a}^{x} m^{\prime} \Psi\left(\frac{\left|v^{\prime}\right|}{m^{\prime}}\right) d t\right) F^{\prime}\left(\int_{a}^{x} r^{\prime} \phi\left(\frac{\left|u^{\prime}\right|}{r^{\prime}}\right) d t\right) r^{\prime} \phi\left(\frac{\left|u^{\prime}\right|}{r^{\prime}}\right)\right] d x \\
= & \int_{a}^{b} \frac{d}{d x}\left[F\left(\int_{a}^{x} r^{\prime} \phi\left(\frac{\left|u^{\prime}\right|}{r^{\prime}}\right) d t\right) G\left(\int_{a}^{x} m^{\prime} \Psi\left(\frac{\left|v^{\prime}\right|}{m^{\prime}}\right) d t\right)\right] d x \\
= & F\left(\int_{a}^{b} r^{\prime} \phi\left(\frac{\left|u^{\prime}\right|}{r^{\prime}}\right) d t\right) G\left(\int_{a}^{b} m^{\prime} \Psi\left(\frac{\left|v^{\prime}\right|}{m^{\prime}}\right) d t\right) .
\end{aligned}
$$


This is the required inequality in (3).

In order to prove the inequality (4), we first observe that having $\int_{a}^{b} p(x) d x=$ 1 , by assumption, we can write

$$
\int_{a}^{b} r^{\prime} \phi\left(\frac{\left|u^{\prime}\right|}{r^{\prime}}\right) d x=\frac{\int_{a}^{b} \frac{\operatorname{pr}^{\prime} \phi\left(\frac{\left|u^{\prime}\right|}{r^{\prime}}\right)}{p} d x}{\int_{a}^{b} p d x}
$$

and

$$
\int_{a}^{b} m^{\prime} \Psi\left(\frac{\left|v^{\prime}\right|}{m^{\prime}}\right) d x=\frac{\int_{a}^{b} p m^{\prime} \frac{\Psi\left(\frac{\left|v^{\prime}\right|}{m^{\prime}}\right)}{p} d x}{\int_{a}^{b} p d x}
$$

Since $h$ is convex, from (16) and (17) and using Jensen's inequality [2, p. 133], we obtain

$$
h\left(\int_{a}^{b} r^{\prime} \phi\left(\frac{\left|u^{\prime}\right|}{r^{\prime}}\right) d x\right) \leq \int_{a}^{b} p h\left(\frac{r^{\prime} \phi\left(\frac{\left|u^{\prime}\right|}{r^{\prime}}\right)}{p}\right) d x
$$

and

$$
h\left(\int_{a}^{b} m^{\prime} \Psi\left(\frac{\left|v^{\prime}\right|}{m^{\prime}}\right) d x\right) \leq \int_{a}^{b} p h\left(\frac{m^{\prime} \Psi\left(\frac{\left|v^{\prime}\right|}{m^{\prime}}\right)}{p}\right) d x
$$

which implies

$$
\int_{a}^{b} r^{\prime} \phi\left(\frac{\left|u^{\prime}\right|}{r^{\prime}}\right) d x \leq h^{-1}\left(\int_{a}^{b} p h\left(\frac{r^{\prime} \phi\left(\frac{\left|u^{\prime}\right|}{r^{\prime}}\right)}{p}\right) d x\right)
$$

and

$$
\int_{a}^{b} m^{\prime} \Psi\left(\frac{\left|v^{\prime}\right|}{m^{\prime}}\right) d x \leq h^{-1}\left(\int_{a}^{b} p h\left(\frac{m^{\prime} \Psi\left(\frac{\left|v^{\prime}\right|}{m^{\prime}}\right)}{p}\right) d x\right) .
$$

Now using (20) and (21) on the right side of inequality (3) we get the required inequality in (4). This completes the proof of Theorem 1. 
The proof of Corollary 2 is immediate, if we take $G(z)=z$ and hence $G^{\prime}(z)=1$ and $m=r, v=u$ and $\Psi=\phi$.

Remark 2. We note that in the special case when $G(z)=1$ and hence $G^{\prime}(z)=0$ and $m=r, v=u, \Psi=\phi$, the inequality (3) reduces to the inequality (2) given by Rozanova in [7]. If we take $m=r, v=u, \Psi=\phi, G=F$ in (3), then we get

$$
\begin{aligned}
& \int_{a}^{b} F\left(r \phi\left(\frac{|u|}{r}\right)\right) F^{\prime}\left(r \phi\left(\frac{|u|}{r}\right)\right) r^{\prime} \phi\left(\frac{\left|u^{\prime}\right|}{r^{\prime}}\right) d x \\
\leq & \frac{1}{2}\left\{F\left(\int_{a}^{b} r^{\prime} \phi\left(\frac{\left|u^{\prime}\right|}{r^{\prime}}\right) d x\right)\right\}^{2} .
\end{aligned}
$$

Further, if we take $F(z)=z^{q+1}$, where $q \geq 0$ is a constant and hence $F^{\prime}(z)=$ $(q+1) z^{q}$ in $(22)$ we get

$$
\begin{aligned}
& \int_{a}^{b}\left[r \phi\left(\frac{|u|}{r}\right)\right]^{2 q+1} r^{\prime} \phi\left(\frac{\left|u^{\prime}\right|}{r^{\prime}}\right) d x \\
\leq & \frac{1}{2(q+1)}\left(\int_{a}^{b} r^{\prime} \phi\left(\frac{\left|u^{\prime}\right|}{r^{\prime}}\right) d x\right)^{2(q+1)} .
\end{aligned}
$$

Putting $\phi(z)=z$ and $2 q+1=n$ in (23) and using Hölder's inequality with indices $n+1$ and $\frac{n+1}{n}$ on the right side of the resulting inequality we get the inequality (8) with $q=n$, which in turn yields the Opial's inequality given in [3, Theorem $2^{\prime}$, p. 154] when $n=1$. We also note that in the special cases the inequality (4) yields the various inequalities as discussed above. For further special versions of the inequalities given in (3) and (4), see [6].

\section{References}

[1] E. K. Godunova and V. I. Levin, "On an inequality of Maroni (Russian)", Mat. Zametki 2 (1967), 221-224.

[2] A. Kufner, O. John and S. Fucik, "Function spaces", Noordhoff International Publishing Leyden, 1977.

[3] D. S. Mitrinović, "Analytic Inequalities", Springer-Verlag, Berlin, New York 1970.

[4] C. Olech, "A simple proof of a certain result of Z. Opial", Ann. Polon. Math. 8 (1960), 61-63. 
[5] Z. Opial, Sur uné inégalité, Ann. Polon. Math. 8 (1960), 29-32.

[6] B. G. Pachpatte, "On integral inequalities similar to Opial's inequality", Demorstratio Math. 22 (1989), 21-27.

[7] G. I. Rozanova, "Integral inequalities with derivatives and with arbitrary convex functions (Russian)", Moskov. Gos. Ped. Inst. Vcen Zap. 460 (1972), 58-65.

[8] G. S. Yang, "On a certain result of Z. Opial", Proc. Japan Accd. 42 (1966), 78-83.

Department of Mathematics and Statistics, Marathwada University, Aurangabad 431004, (Maharashtra), India. 